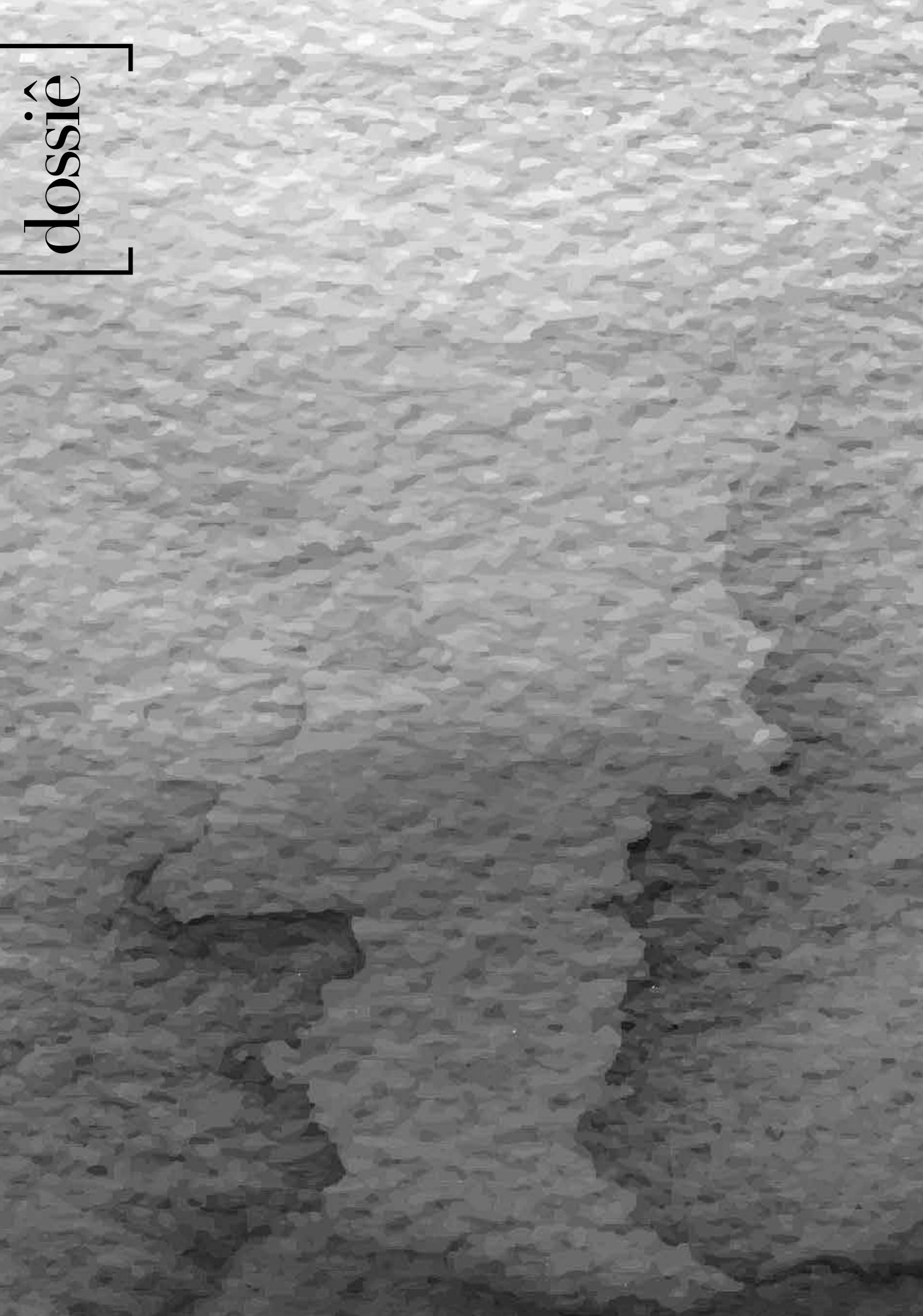



dossiê: imagens da moda e do vestuário ]

[LAURA FERRAZZA DE LIMA]

Doutora em História pela Pontifícia Universidade Católica - PUC-RS.

Pós-doutoranda no Programa de Pós-Graduação em História da

Universidade Federal do Rio Grande do Sul.

laura_de_lima@yahoo.com.br

\title{
A moda em movimento: a obra de Antoine Watteau (1684-1721) e as origens modernas de um fenômeno
}

\author{
The fashion in moving: the art of Antoine \\ Watteau (1684-1721) and the modern \\ origins of a phenomenon
}

[resumo] 0 presente artigo tem por objetivo apresentar um novo conceito do fenômeno histórico da moda. A construção dessa teoria ocorreu ao se voltar 0 olhar para as origens do processo moderno da moda no século XVIII francês. Por meio da análise de parte da obra artística de Antoine Watteu (1684-1721), relacionando-a com a moda de seu tempo e com imagens de outras temporalidades, obteve-se como resultado uma pesquisa inédita tanto no Brasil como no exterior. Analisando o traje como elemento essencial dentro da construção da visualidade do artista, foi possível perceber a moda como um fenômeno sociocultural pautado por um constante movimento entre mudanças e permanências.

[palavras-chave

história da moda; história da arte; moda do século XVIII; Antoine Watteau; vestido Watteau.

[abstract] This article presents a new concept of the historical phenomenon of fashion. The construction of such a theory happened to go back to the origins of modern fashion process in the French eighteenth century. Through the analysis of the artistic work of Antoine Watteu (1684-1721) it was possible to relate it to the fashion of their time and other time frames of images. Presenting results in a original research both in Brazil and abroad. Analyzing the costume as an essential element in the construction of the visual artist was possible to see fashion as a sociocultural phenomenon marked by a constant movement between changes and continuities.

[keywords] fashion history; history of art; fashion eighteenth century; Antoine Watteau; Watteau dress. 
Este artigo é parte integrante de minhas pesquisas de doutorado, já concluído, e de meu pós-doutorado, ainda em andamento. Tem como eixo central a busca pelas origens da difusão da moda francesa dentro do processo moderno. Por meio da reflexão teórica acerca do estatuto das imagens foi possivel repensar a moda e sua relação com algumas imagens da arte. Em minha tese intitulada: $\mathrm{Na}$ trama das aparências: moda e arte na obra de Antoine Watteau (1684-1721), defendida recentemente ${ }^{1}$, analisei a relação da obra do referido artista francês com a moda. A fonte principal dessa pesquisa foi um conjunto de gravuras em água-forte realizadas com base em desenhos de Watteau, intitulado Recueil Julienne. Essa publicação tem uma importância crucial na história da imprensa ilustrada, das gravuras de moda e da história da arte.

0 contato com essa fonte ocorreu durante meu estágio doutoral na Universidade Paris I - Sorbonne, em História Cultural e Social da Arte. Ela está na Coleção Edmond Rothschild do Museu do Louvre. Além das fontes imagéticas, pude visitar o acervo do Museu Galliera, setor de indumentária do século XVIII, a fim de ver exemplares originais da moda do período estudado. 0 uso de fontes documentais pouco exploradas e a escolha pelo tema que relaciona a moda com a produção artística de Antoine Watteau resultou na elaboração de uma pesquisa inédita tanto no Brasil como no exterior.

As possiveis relações entre a obra de Watteau e a moda já haviam sido notadas antes'i faltava, contudo, um olhar mais aprofundado sobre o tema. Tive a oportunidade de realizar essa detida e minuciosa mirada sobre as fontes citadas, além da observação direta das pinturas do artista expostas no Museu do Louvre na seção de pintura francesa do século XVIII. Dessa maneira, pude ter uma experiência visual das imagens originais, não mediada por reproduções, uma vez que a reprodução leva à perda da aura, segundo Walter Benjamin (BENJAMIN, 2013, p. 49).

A fim de unir campos do conhecimento tais como a história da moda e a história da arte, escolhi como caminho o debate sobre a questão das imagens. Uma abordagem multidisciplinar é de grande pertinência para pensar a respeito de um pintor complexo, cuja obra estabelece diversas relações. Afinal, de que maneira a obra de Watteau se relaciona com a moda não apenas da França de seu tempo, mas com a história da moda como um todo? Essa questão está intrinsecamente ligada a uma outra: as imagens de Watteau criam a moda ou elas representam modelos que já estão em moda?

Ao procurar responder esses questionamentos, refleti sobre a maneira com que o traje e/ou a moda participaram na constituição da visualidade do artista expressa em suas obras. Além disso, procuro analisar a construção da memória em torno dos trajes presentes nas obras de Watteau - em algumas pinturas e principalmente nas gravuras, que serviram como fonte principal. É necessário percorrer, através das imagens selecionadas, o território que os trajes e a moda ocuparam na obra do artista. Por fim, procuro destacar o papel desempenhado pela roupa na construção da gestualidade e do movimento das figuras desenhadas pelo artista e reproduzidas no conjunto de gravuras que serve como fonte principal de minhas pesquisas. 
A escolha por pinturas e gravuras deve-se à importância da reflexão sobre a historicidade das imagens. Nesse sentido, é pertinente ponderar sobre quais relações as imagens selecionadas estabelecem com as sociabilidades e as formas de vestir da época em que foram produzidas. Consequentemente, é preciso analisar a estrutura do traje do século XVIII, que atribui uma forma específica ao corpo e modela seus movimentos. Ao fazer essa análise, considerei de que maneira as imagens selecionadas apresentam as formas vestimentares e colaboram na construção do fenômeno da moda.

A fim de melhor responder aos problemas propostos até aqui, é importante refletir sobre o estatuto próprio das imagens. A imagem joga com a temporalidade e com a memória. "Diante de uma imagem, o passado nunca para de se reconfigurar, uma vez que a imagem deve ser pensada sempre numa construção da memória" (DIDI-HUBERMAN, 2011, p. 32). Dessa maneira, é preciso considerar que diferentes memórias também realizaram seu trabalho de construção nas imagens produzidas pelo artista Antoine Watteau. A memória é imprecisa e capaz de mesclar diferentes temporalidades, assim como as imagens.

Compreender e aceitar a dimensão anacrônica das imagens e da própria história é inevitável. Afinal, é impossivel interpretar o passado sem recorrer ao presente. 0 historiador deve considerar que o tempo que analisa não é exatamente o passado, mas a memória: "É ela que decanta o passado de sua exatidão. É ela que humaniza e configura o tempo, entrelaça suas fibras, assegura suas transmissões, consagrando-o a uma impureza essencial" (DIDI-HUBERMAN, 2011, p. 60). Podemos dizer que o tempo é como as fibras de um tecido tramado pela memória. Por isso minha investigação recai mais propriamente sobre a memória acerca das obras de Watteau e sua relação com a moda.

Essa relação começou a ser delineada pelo uso de um termo destacado na história da moda, mas que carece de uma investigação mais aprofundada. Nos grandes compêndios de história da indumentária, encontramos com frequência a classificação de um modelo específico de vestido do início do século XVIII como "vestido Watteau" ou "vestido com pregas Watteau". Em minha tese procurei desvendar a origem da expressão e descobrir o motivo pelo qual uma peça do vestuário feminino foi associada ao nome desse artista.

Ao analisar as alterações na estrutura do traje feminino francês do início do século XVIII, o historiador da vestimenta François Boucher coloca uma questão interessante sobre Watteau. Segundo ele, entre os anos de 1705 e 1715 , surgiu a moda dos vestidos não rígidos, também chamados de vestidos volantes, "que foram englobados sob a denominação simplista de vestidos de Watteau, sendo que o pintor não interveio em absoluto na sua criação" (BOUCHER, 2009, p. 263).

É certo dizer que o pintor não criou tais vestidos à maneira dos estilistas de moda contemporâneos, mas por qual motivo seu nome estava associado a eles? É importante destacar o fato de que um artista renomado se dedicou a desenhar figurinos de moda e que, em suas obras, a vestimenta aparenta ter um papel de destaque. 0 vestido volante deve seu nome às suas grandes pregas, muito características. Elas partiam dos ombros do manto, desenrolavam-se sobre a saia e flutuavam livremente até o solo, podendo ser

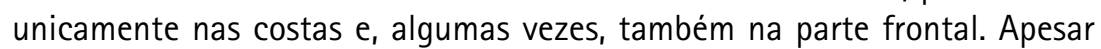
do corpete apertado sob o manto e o panier encoberto pela saia, esse vasto vestido dava a impressão de ser confortável e agradável de usar. Como podemos observar na Figura 1: 


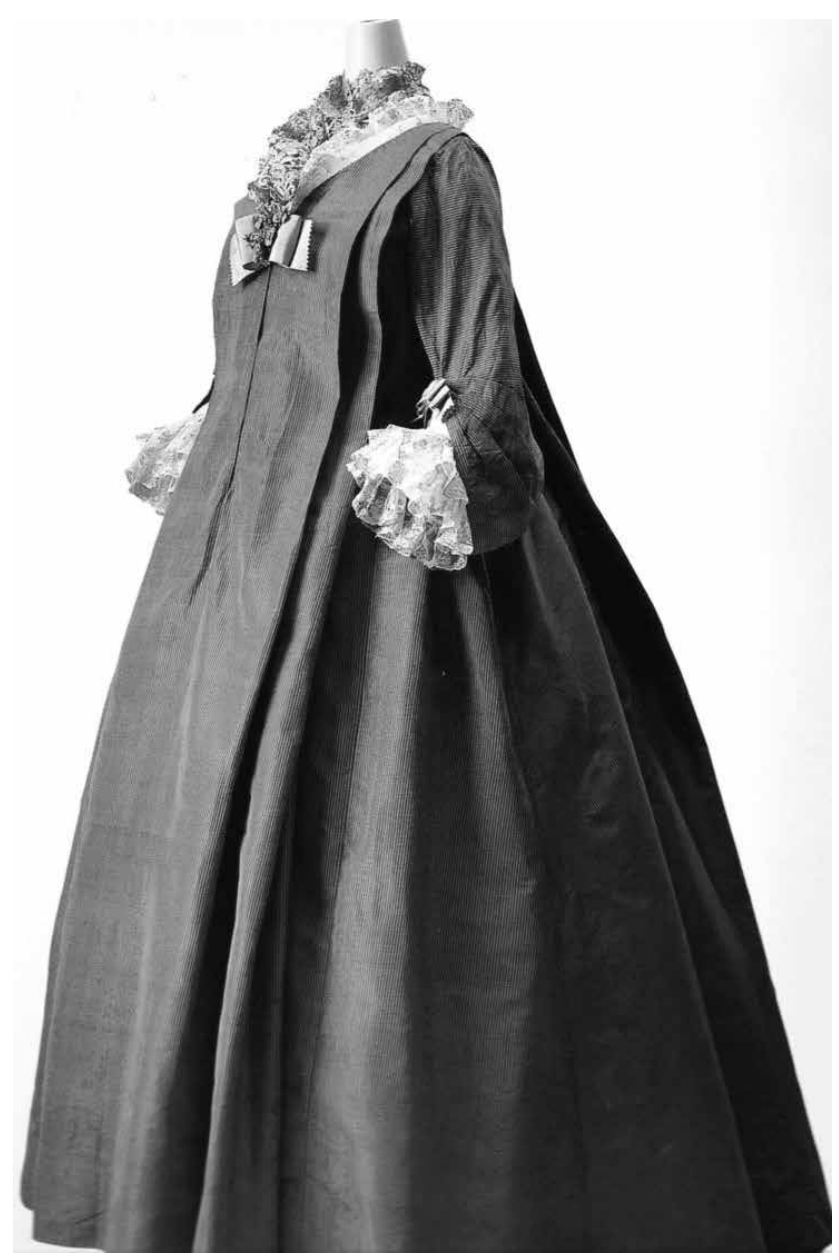

$[\mathrm{I} 3]$

Figura 1 - Um exemplo de vestido volante, 1720.

Fonte: INSTITUTO DE LA INDUMENTARIA DE KIOTO. Moda: una historia desde el siglo XVIII al siglo XX. Tomo I: siglo XVIII y siglo XIX. Colônia: Taschen, 2006.

Alguns autores afirmam que o nome de Watteau é inseparável do traje do periodo da Regência (1715-1723). Contudo, alertam que é preciso estabelecer diferenças "(..) entre a parte de sua obra que é puramente imaginação e fantasia, como seus personagens da Comédia italiana, e aquelas que reproduzem quase fielmente a realidade" (RUPPERT, 2007, p. 140). Essa afirmação nos leva a realizar importantes reflexões. Por um lado, é difícil separar, na obra de Watteau, o momento em que ele representa unicamente personagens do teatro - tanto da commedia dell'arte italiana quanto da comedie française - e tipos sociais. Parece-nos que realidade e ficção, teatro e vida cotidiana, idealização e fantasia, todos esses elementos se confundem em sua obra, fazendo com que o traje teatral e o traje cotidiano se entrelacem de tal maneira que fica difícil distingui-los. Sobre a afirmação que considera que 0 pintor realizou a representação mais ou menos fiel da realidade, consideramos um tanto questionável. A imagem nunca deve ser tomada como representação fiel do real. No caso das vestimentas, podemos falar de um certo grau de verossimilhança. 
Pesquisar a moda dentro da instituição acadêmica atualmente é abrir um amplo leque de imagens que vêm sendo produzidas há séculos. Uma das fontes para esse tipo de pesquisa são as gravuras de moda ou fashion plates: imagens específicas que foram criadas com o objetivo de mostrar os trajes. As fashion plates começam a surgir na França nas últimas décadas do século XVII, veiculadas principalmente pelo jornal ilustrado Mercure Galant(1672-1724). Antes disso, já existiam os chamados costume plates, que registravam modismos depois que estes já estavam estabelecidos; eram consumidos por um público reduzido, que se limitava a aristocratas curiosos, profissionais da moda de alto nível e artistas em busca de modelos (ROCHE, 2007). A novidade das fashion plates é que, por um lado, elas indicavam o que as pessoas deveriam usar para estar na moda - não eram um simples registro, mas uma espécie de guia de estilo; por outro lado, destinavam-se a um público mais amplo, tendo papel importante na divulgação e popularização das vestimentas. Além dessas imagens ligadas de forma direta à moda, existem outras, que representam o fenômeno de forma indireta: pinturas e gravuras que apresentam detalhes das vestimentas. Imagens desse tipo, Watteau as produziu em quantidade. Quanto às fashion plates, o artista não chegou a produzi-las, mas sua obra está, de certa forma, vinculada a elas. Isso porque as Figuras de Diferentes Caracteres, produzidas com base nos desenhos de Watteau, têm várias caracteristicas em comum com as gravuras de moda.

A moda, como a conhecemos hoje, é um fenômeno caracterizado por mudanças rápidas, exercendo grande impacto sobre os individuos. Mas quando isso começou a acontecer? Alguns autores que se dedicaram a responder essa questão apontam o século XVIII como o momento de virada em que a moda passou a apresentar essas características ${ }^{3}$. A sociedade dessa época exaltou o prazer imediato, como se o presente fosse a única dimensão temporal válida. Eles partilhavam em certa medida da ideia de que havia relações intrincadas no mundano e de que nele residiria o fim último da existência. Portanto, configura-se como momento privilegiado para o estudo do fenômeno da moda, pois foi a época que a exaltou e a alçou à categoria sine qua non de existência.

As ideias vigentes no século XVIII sobre o valor do mundano apresentam ligações produtivas com certos aspectos filosóficos do estudo das aparências daquilo que está na superfície dos objetos. Segundo Svendsen, "vai um pouco contra a natureza da filosofia escrever sobre moda" (SVENDSEN, 2010, p. 19). Ele se refere à tradição platônica, que coloca a realidade de um lado e as aparências de outro. Apesar disso, o autor conclui que "a moda é pura superfície". Assim como os antigos céticos afirmavam que o mundo fenomênico contém suficientes complexidades para embasar e instigar o conhecimento, também na moda - considerada superfície e aparência - encontram-se relevantes fenômenos a se analisar para a história.

Sobre a velocidade moderna das transformações no século XVIII, Gilles Lipovetsky (2003) afirma que entre os séculos XIV e XIX, as flutuações da moda seguramente não conheceram sempre as mesmas precipitações. Durante a Idade Média os ritmos da mudança teriam sido menos espetaculares do que no Século das Luzes, em que os modismos disparam, se alteram "todos os meses, todas as semanas, todos os dias, quase a cada hora" (LIPOVETSKY, 2003, p. 30).

Do ponto de vista filosófico e histórico, as "luzes" estão relacionadas aos filósofos franceses e ao pensamento político. Atualmente, o termo generalizou-se, e isso, em certa medida, desgastou-o. Contudo, ele ainda nos remete inescapavelmente ao século XVIII, visto como a época da origem de nossa modernidade. No plano intelectual, os filósofos desse período mesclam temas de estudo da Antiguidade com uma espécie de libertinagem erudita, construída por meio da oposição à lgreja. 
Enquanto tais reflexões eram elaboradas, as cidades cresciam e exigiam uma nova organização. Houve um aumento na demanda por produtos variados e 0 incentivo do consumo por meio de uma imprensa de anúncios. A progressiva comercialização do lazer determinou o curso da Revolução Industrial. Havia uma propensão de consumo fundada sobre a pujança simbólica do luxo, de uma certa imitação das elites e do poder infinito da moda para popularizar a si mesma. Assim, os consumidores buscavam produtos que podem ser ditos de luxo ou semiluxo, uma vez que todo luxo é relativo, incluindo-se aí utensílios de mesa, toalete, decoração etc.

É possivel observar, nesse período, uma mudança secular das atitudes e dos valores da classe média, que buscava um prazer imaginário, puramente emocional, fundado sobre o consumo da novidade (POULOT, 2000). Isso possibilitou uma motivação para a moda, o amor romântico e a literatura romanesca. 0 consumo tornou-se sentimental, hedonista e individualista, como uma maneira de secularizar o sentimento religioso, contribuindo para a criação de uma cultura específica, que levou ao gosto pelo decorativo em todos os setores. A ambientação dos salões e dos lugares de comércio era feita para encantar os frequentadores e os clientes segundo a crença sensualista. 0 consumo massivo ocorre antes de tudo em termos de alimentação: chá, café, chocolate (que exige o açúcar); na sequência imediata, vêm as vestimentas e os acessórios. Contudo, as preocupações intelectuais das Luzes não incluiam condenações do consumo nem reprimendas aos consumidores - pelo contrário. Na Enciclopédia, o verbete "luxo" foi escrito por Saint-Lambert. Em lugar de vociferar contra a ociosidade, as modas, a frivolidade, os prazeres, 0 autor celebra o luxo como um elemento-chave da sociedade próspera, moral e racional: nele, o prazer do homem rico une-se aos trabalhos das artes liberais e mecânicas e ao labor dos negócios. Dessa maneira, o luxo participa no "espírito de comunidade" (POULOT, 2000, p. 16). 0 argumento de Saint-Lambert é mais uma evidência de que a sociedade na qual Watteau viveu era profundamente permeável à questão da moda.

Segundo Lars Svendsen, "(o) desenvolvimento da moda foi um dos eventos mais decisivos da história mundial, porque indicou a direção da modernidade" (SVENDSEN, 2010, p. 25). Entretanto, ela apresenta um elemento incômodo para o pensamento moderno, pois é uma manifestação tida como irracional. Representa a mudança pela mudança e contraria a noção de que, na modernidade, as alterações levariam a ações baseadas na razão.

Considerando que as imagens congregam múltiplas temporalidades e que há uma relação latente entre elas e a moda, podemos concluir que esta última também é composta por um entrecruzamento de referências temporais. A moda, apesar de exaltar a novidade, nunca é completamente nova; existem sobrevivências bem como permanências, como no caso dos tecidos, das estruturas do traje, entre outras. Porém, novos tecidos podem surgir, assim como novas técnicas, cores e formas. A união entre os tempos, a confusão entre passado, presente e até futuro, também vive nas roupas e, por conseguinte, na moda.

Jean Claude Schmitt (2007) chama a atenção para o lugar central que as imagens ocupam na cultura ocidental. Devemos lembrar que o homem as produzia antes de possuir uma língua - e, consequentemente, antes da escrita, uma vez que no paleolítico já havia pinturas rupestres. Um dos campos aqui em análise -a moda - manifesta-se principalmente por meio de imagens. A descrição escrita ou verbal de um traje não é tão eficiente quanto algumas de suas formas figurativas (gravura, fotografia etc.). Além disso, a roupa pode ser considerada a materialização tátil de uma imagem que a representa. 
Uma vez que o homem constrói seu pensamento como uma montagem de referências visuais e a moda é uma manifestação visual, analisar imagens de moda torna-se importante para compreender o próprio funcionamento da memória humana. Nas palavras de Schmitt: "Toda imagem visa tornar-se um 'lugar de memória'; a memória individual, mas também a memória coletiva em todas as suas dimensões sociais e culturais, consiste antes de tudo em imagens" (SCHMITT, 2007, p. 46). Afinal, as imagens interferem na construção do imaginário coletivo.

Para Baumer, a pintura do século XVIII expressava "sensualidade e liberdade em relação a qualquer espécie de responsabilidade social" (BAUMER, 1990, p. 192). Ela pode ser associada com a valorização da temporalidade do instante $e$ relaciona-se com a sociedade por meio do estímulo aos prazeres mundanos e 0 gosto pela intimidade, elementos que podem ser associados ao igualmente fugidio fenômeno da moda. A satisfação dos desejos íntimos levou à valorização de esferas que estão mais relacionadas com a pessoa. A partir de então, a produção de móveis, vestuário e decoração interior ganha destaque. Uma vez que o gosto está submetido ao prazer individual, a necessidade de renovar as fontes de satisfação levará à busca por novidades tanto na arte como na moda.

De maneira alguma as imagens que analiso são consideradas apenas a representação da vida, da sociedade e mesmo da moda do século XVIII francês. Reduzi-las à categoria de representação seria extrair delas a camada mais superficial; seria vê-las apenas como interesse documental com um certo caráter positivista. A imagem é mais complexa em sua natureza e razão de ser. "As próprias imagens conseguem mais de uma vez lembrar que sua função é menos representar uma realidade exterior do que construir o real de um modo que lhe é próprio" (SCHMIT, 2007, p. 27). É preciso pensar na imagem como uma suspensão, um instante único apreendido a partir de uma realidade muito mais ampla. Assim, é lícito indagar-se de que maneira as imagens selecionadas construiram uma ideia - que pode ser equivocada, limitada ou verossímil - da moda do século XVIII.

Segundo Helmut Börsch-Supan (2007, p. 76), as palavras "moda" (fashion) e "modo" (mode) em inglês derivam do francês. Esses termos ganharam um grande significado na mudança dos estilos de vida a partir do século XVII na França. As constantes mudanças na moda a partir desse período evidenciam a importância dada ao momento presente e à renovação das sensações.

A moda é um desses fenômenos que transpassam o tempo e se mesclam à vida sem que as pessoas reflitam muito a respeito. Contudo, alguns pensadores notaram o poder de síntese social representado pelo que vestimos. "A moda se faz sentir em quase todas as áreas da vida, mas especialmente no vestir, já que as pessoas usam roupas que revelam o que gostariam de ser" (BÖRSCH-SUPAN, 2007, p. 76). 0 fenômeno não deve ser considerado uma mera distinção entre classes, pois isso apagaria seu potencial enquanto distinção entre os indivíduos, seu papel na criação de uma identidade.

Em minhas pesquisas, procuro me libertar ao máximo de conceitos que possam limitar a análise, como estilo e época. Afastar as obras que selecionei de um rótulo estilístico não é tão difícil, uma vez que o pretenso estilo ao qual elas poderiam pertencer - o Rococó - parece bastante problemático em sua construção; de qualquer forma, todas as designações desse tipo são bastante artificiais. Em Architecture du baroque tardif et rococo, Christian Norberg-Schulz pergunta-se

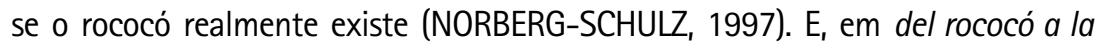
revolución, Levey especula: "Quem sabe seja falso dizer que tenha existido uma pintura rococó" (LEVEY, 1998, p. 15). Se não podemos falar de um estilo rococó para a arte, tampouco podemos fazê-lo em relação à moda. Se acaso o fizéssemos, estariamos colocando um rótulo demasiado redutor nas imagens.

A memória que habita as imagens não é apenas de um único momento histórico, do passado. As imagens são "receptáculos inesgotáveis de recordações, 
matéria de sobrevivências" (DIDI-HUBERMAN, 2010, p. 160). Além disso, a imagem pode ser também um sintoma. Nesse sentido, Didi-Huberman trabalha com o conceito de imagem-malícia: "Falar de imagem-malícia é, antes de tudo, falar de mal-estar na representação" (DIDI-HUBERMAN, 2010, p. 178). Não se trata apenas de choques de temporalidades, mas de significados mais amplos, que perturbam de alguma forma o conjunto da obra.

Essa definição deve levar a um questionamento sobre as imagens que selecionamos para uma pesquisa: elas podem ser classificadas como imagens-malícia? É preciso verificar se há algo que cause algum tipo de incômodo na representação. No caso das fontes visuais com as quais trabalho tenho a impressão de que esse fator aparece justamente nos trajes. Quando apuramos o olhar sobre as vestimentas retratadas por Watteau, perturba a ideia de que elas sejam representações da moda de sua época. Isso porque percebemos que, na verdade, essas imagens são uma mescla diversa, capazes de unir, pela mão do artista, a dança, o teatro e a moda.

0 conceito de pathosformeln foi pensado por Warburg a respeito do gesto e do movimento na arte do Renascimento. Por meio dessa reflexão, o teórico criou uma verdadeira "antropologia histórica dos gestos (...) que fosse capaz de examinar a constituição técnica e simbólica dos gestos corporais numa dada cultura" (SAMAIN, 2012, p. 60). Essa é uma ideia importante, pois possibilita construir uma reflexão antropológica sobre as imagens, centrada no questionamento: como os trajes ajudam a moldar os gestos nas figuras de Antoine Watteau? Para responder essa questão, analisei detidamente a vestimenta e o gestual de algumas das figuras desenhadas pelo artista e reproduzidas em gravura.

Um exemplo seria a prancha 2 (Figura 2) do primeiro tomo das Figuras de Diferentes Caracteres. Nela, vemos uma mulher em posição que remete a um passo de dança. Ela está de pé, com o rosto e o corpo de perfil. 0 braço esquerdo encontra-se estendido, enquanto o direito segura a saia. 0 pé que surge sob a saia parece estar em ponta.

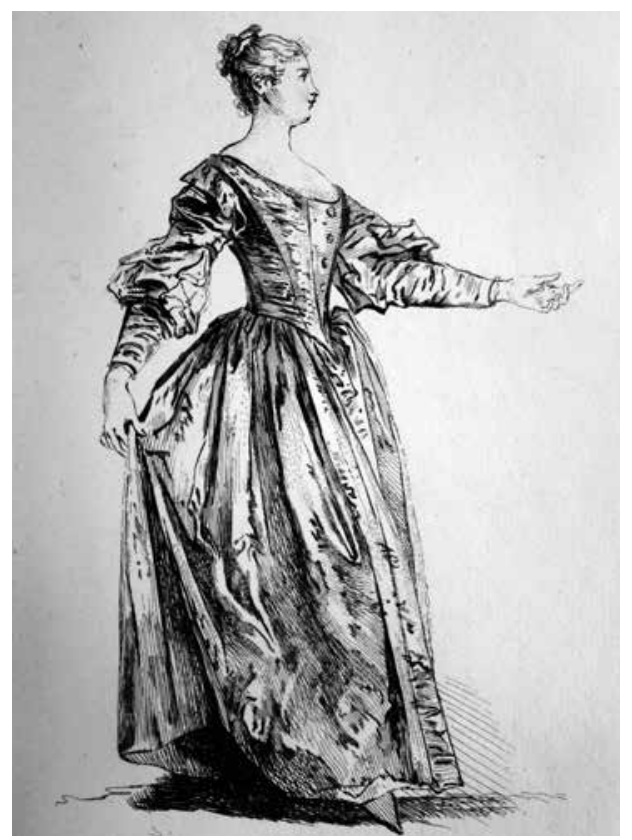

Figura 2 - Prancha 2 do Tomo I das Figuras de Diferentes Caracteres. Gravura em águaforte, 1726 .

Fonte: Arquivos do Museu do Louvre. Coleção Edmond Rothschild. Paris. Fotografia: acervo 
pessoal.

Além da posição de seu corpo, o traje também auxilia a deduzir que se trata de uma dançarina. Ela usa um espartilho ajustado com um peitilho decorado com o que parecem ser pequenos botões. As mangas do vestido são bufantes na altura dos cotovelos. A saia é bastante franzida abaixo do corpete, que termina numa acentuada ponta frontal. 0 traje é bem diferente do vestido volante usado normalmente na época de Watteau. Há inúmeras características que diferenciam essa roupa dos trajes cotidianos das mulheres do período, levando-nos a crer que se trata de um figurino.

0 cabelo está arrumado segundo a moda da época, mas chama a atenção o colo e o pescoço desnudos, sem nenhum adorno. É como se o artista quisesse destacar as partes desnudas do corpo. 0 rosto possui uma expressão delicada, quase etérea. Apesar de um sombreado que representa o chão, temos a impressão de que a mulher flutua sob a saia ao dançar.

É importante destacar que o viés da moda permite ver o artista e sua obra de forma não linear, sob o ângulo de diversas temporalidades. Podemos dizer que Watteau era profundamente sensivel à moda, pois esta se encontra presente, de forma marcante, tanto em suas pinturas como em seus desenhos. A dimensão que o traje ocupa em sua obra é inegável. Ele estabelece um diálogo com a questão das aparências, muito cara à sociedade na qual Watteau viveu e produziu; sua relação com a moda, no entanto, não se limita a essa associação.

Nas imagens de Watteau, a roupa não é apenas um adorno esvaziado de sentido. Não está presente apenas para embelezar os corpos ou as figuras. Existe um diálogo entre o traje e a expressão dos gestos e dos sentimentos. 0 mesmo diálogo também se estabelece entre a vestimenta e o ambiente que circunda 0 personagem. Pode-se dizer que o traje compõe fundamentalmente a imagem, formando o caráter da figura.

A roupa ajuda a construir ou reforçar uma identidade, tanto na obra de Watteau como no universo da moda em geral. As vestimentas representadas por ele nem sempre apresentam acuidade histórica; mesmo assim, podemos encontrar nelas algumas características associadas a determinado grupo social ou profissional. Além disso, o traje, ainda que imaginário, determina de forma nítida elementos mais básicos, como o sexo do personagem.

A relação do artista com a moda parece oscilar entre a admiração e, talvez, a crítica. Isso pode ser apreendido pela relação entre as obras de Watteau e 0 teatro. Trata-se de um diálogo inegável, que serve para elucidar e compreender os trajes desenhados pelo artista. 0 possível traço crítico vem à tona na escolha de Watteau por mesclar roupas da moda com figurinos inspirados em comédias obras que tratavam a sociedade da época com uma dose de ironia. 0 teatro não é expresso, nessas imagens, de maneira direta, mas surge pela representação de figuras-tipo, que nem sempre são fáceis de ler ou reconhecer.

As peças cômicas eram imensamente admiradas e valorizadas pela própria sociedade que ironizavam. Watteau utiliza-se da popularidade da comédia para transformar as suas figuras em um espelho obliquo e refratado do mundo social como um todo. Em alguns casos, a referência aos palcos parece funcionar como uma metáfora do teatro social encenado nas fêtes galantes do mundo real. Em todo caso, a principal lição que Watteau parece ter extraído do universo teatral é a ideia de que o traje faz a pessoa - ou, ao menos, indica um desejo de ser e de transformar-se. 0 ato de travestir-se era um dos elementos mais comuns nas peças produzidas e encenadas na época. A troca de roupas não transformava o criado em patrão, mas anunciava o impulso de mudar de identidade e experimentar novas sensações. Vale lembrar que, nesse período, já se anunciava uma certa mistura de classes. Nobres e burgueses ricos casavam entre si, e havia traços em comum nas formas de vestir de ambas as classes (PRAVIS, 1999). À medida que as elites se 
misturavam, o crucial já não era diferenciar burgueses de aristocratas, mas traçar uma fronteira bem clara entre as duas classes superiores e todos aqueles que estavam abaixo delas. Apesar dessa diferenciação, considerada ainda necessária pela sociedade da época, Watteau representava damas elegantes sendo cortejadas por atores de teatro, como podemos ver na prancha 198 do segundo tomo da Figuras de Diferentes Caracteres (Figura 3). Ou seja: pincelava a mescla que já estava ocorrendo, mas, de certa forma, a ironizava, apontando seus limites autoimpostos.

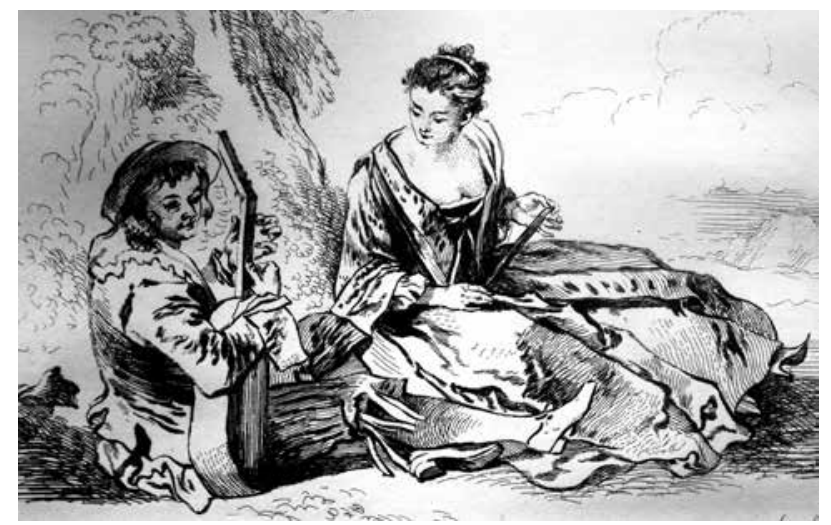

Figura 3 - Prancha 198 do Tomo II das Figuras de Diferentes Caracteres. Gravura em água-forte, 1726.

Fonte: Arquivos do Museu do Louvre. Coleção Edmond Rothschild. Paris. Fotografia: acervo pessoal.

0 artista parecia perceber a moda como um espaço de experimentação: a roupa desenhada podia fundir mundos aparentemente díspares, mas interligados. Os trajes que cobrem suas figuras mantêm sempre a graça e a elegância exigidas pela moda do momento, mas, ao mesmo tempo, flertam com o cômico e o exagero. Muitas vezes, as vestes representadas por Watteau são imaginárias, embora mantenham um caráter verossímil. Além do teatro, o universo da dança e da música também impregnam seus tecidos, brincam entre seus botões. Amantes felizes (Figura 4) e artistas melancólicos (Figura 5) surgem vestidos em criações de Watteau - vestes nascidas de sua fantasia, que em geral não correspondem a um modelo físico.
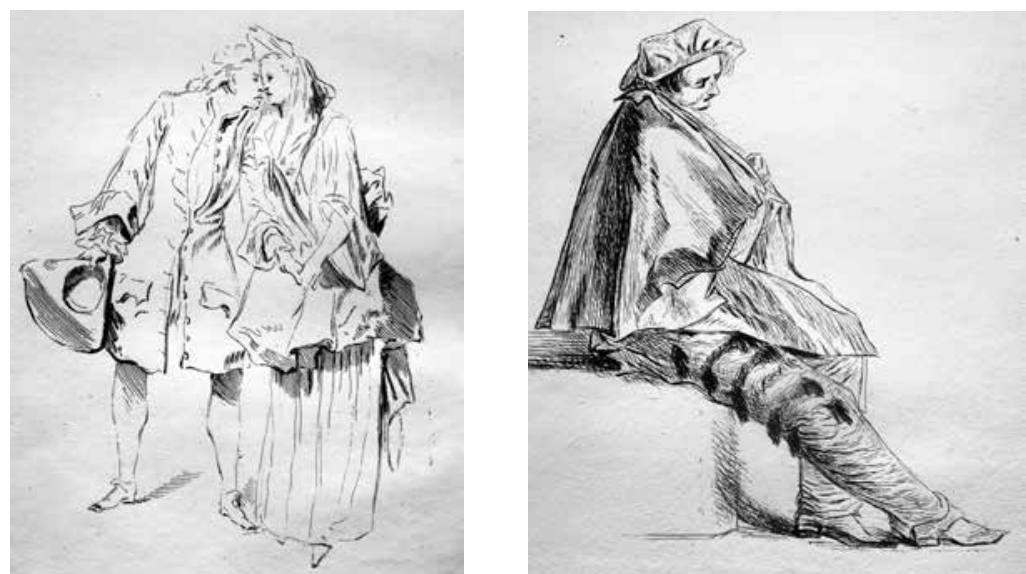

Figuras 4 e 5 - Prancha 190 do Tomo II das Figuras de Diferentes Caracteres e Prancha 151 do Tomo I das Figuras de Diferentes Caracteres.

Fonte: Arquivos do Museu do Louvre. Coleção Edmond Rothschild. Paris. Fotografia: acervo pessoal. 
As fêtes galantes criadas por Watteau se destacaram como espaço para a articulação de diferentes questões pertinentes à moda. Essas imagens apresentam, em certa medida, expressões de festas reais, dos gostos e anseios da sociedade; mas também revelam nuanças do olhar lançado pelo artista sobre a natureza, as atitudes humanas, a sedução amorosa. Nessas imagens, a maneira de vestir dos personagens mostrou-se imprescindivel para uma intrincada construção de sentidos. A roupa e os acessórios conferem às figuras uma posição inesperada e delineiam uma comunicação sem palavras e com economia de gestos (Figura 6); tal comunicação se dá, por exemplo, por meio de uma capa displicentemente jogada no ombro (Figura 7). As dobras do tecido nos apresentam tensões e sensações: a roupa modela os gestos e expressa atitudes (Figura 8). Alguns elementos podem assumir funções diferentes, dependendo do contexto que os cerca. Uma boina caída pode expressar tristeza (Figura 5), mas também galanteria (Figura 9), e sua significação muda conforme a totalidade da imagem. Em uma coquete, um decote pode anunciar o desejo de se deixar seduzir (Figura 10); já o leque, quando fechado, indica hesitação amorosa (Figura 11); quando aberto, é sinal de aceitação (Figura 12) (sobre os códigos do leque: JAMAIN, 2014, p. 273).

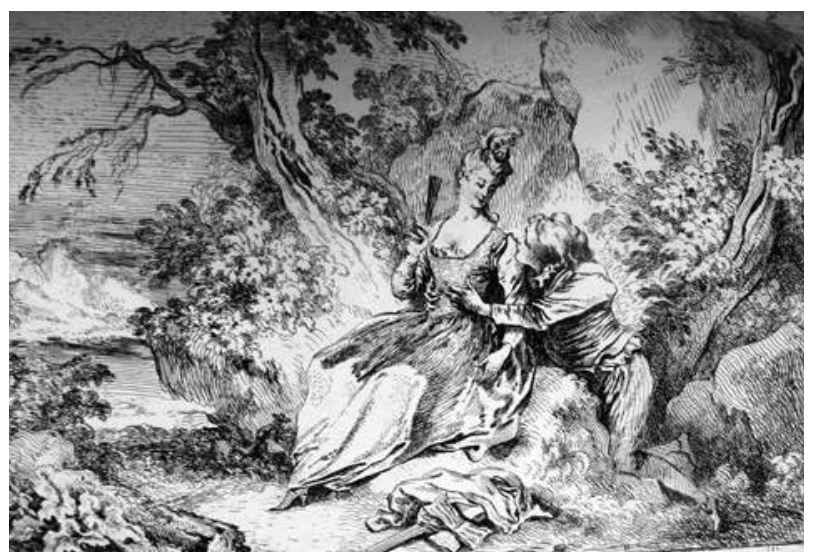

Figura 6 - Prancha 132 do Tomo I das Figuras de Diferentes Caracteres. Uma cena galante. Fonte: Arquivos do Museu do Louvre. Coleção Edmond de Rothschild. Paris. Fotografia: acervo pessoal.

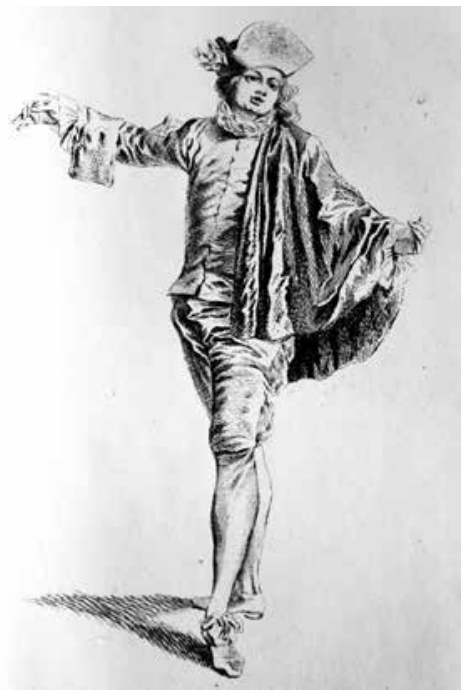

Figura 7 - Prancha 102 do Tomo I das Figuras de Diferentes Caracteres.

Fonte: Arquivos do Museu do Louvre. Coleção Edmond de Rothschild. Paris. Fotografia: acervo pessoal. 


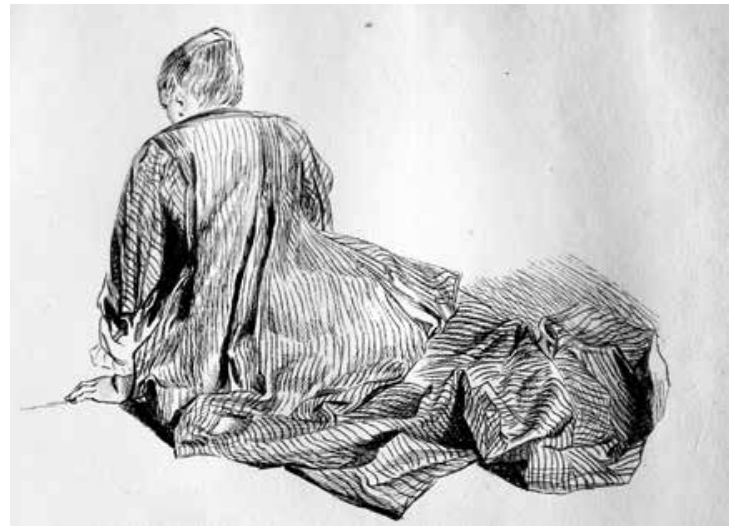

Figura 8 - Prancha 161 do Tomo I das Figuras de Diferentes Caracteres.

Fonte: Arquivos do Museu do Louvre. Coleção Edmond de Rothschild.. Paris. Fotografia: acervo pessoal.

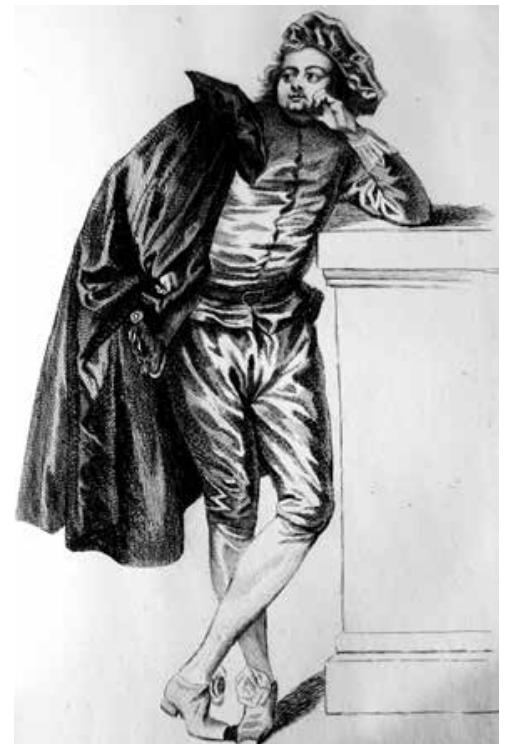

Figura 9 - Prancha 84 do Tomo I das Figuras de Diferentes Caracteres. Fonte: Arquivos do Museu do Louvre. Coleção Edmond de Rothschild. Paris. Fotografia: acervo pessoal.

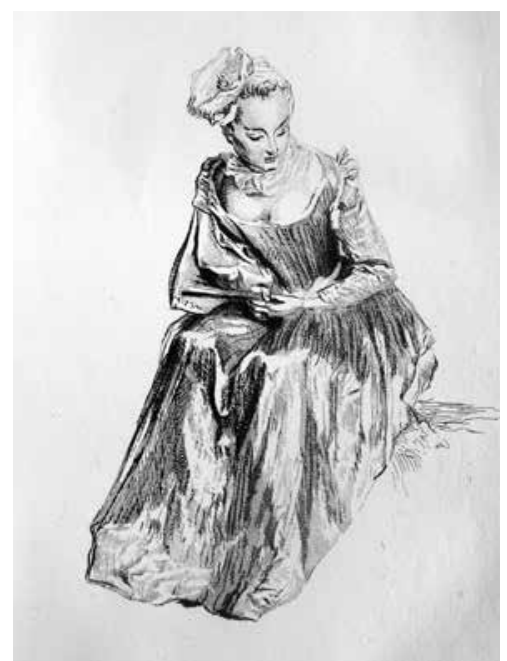

Figura 10 - Prancha 19 do Tomo I das Figuras de Diferentes Caracteres.

Fonte: Arquivos do Museu do Louvre. Coleção Edmond de Rothschild. Paris. Fotografia: acervo pessoal. 

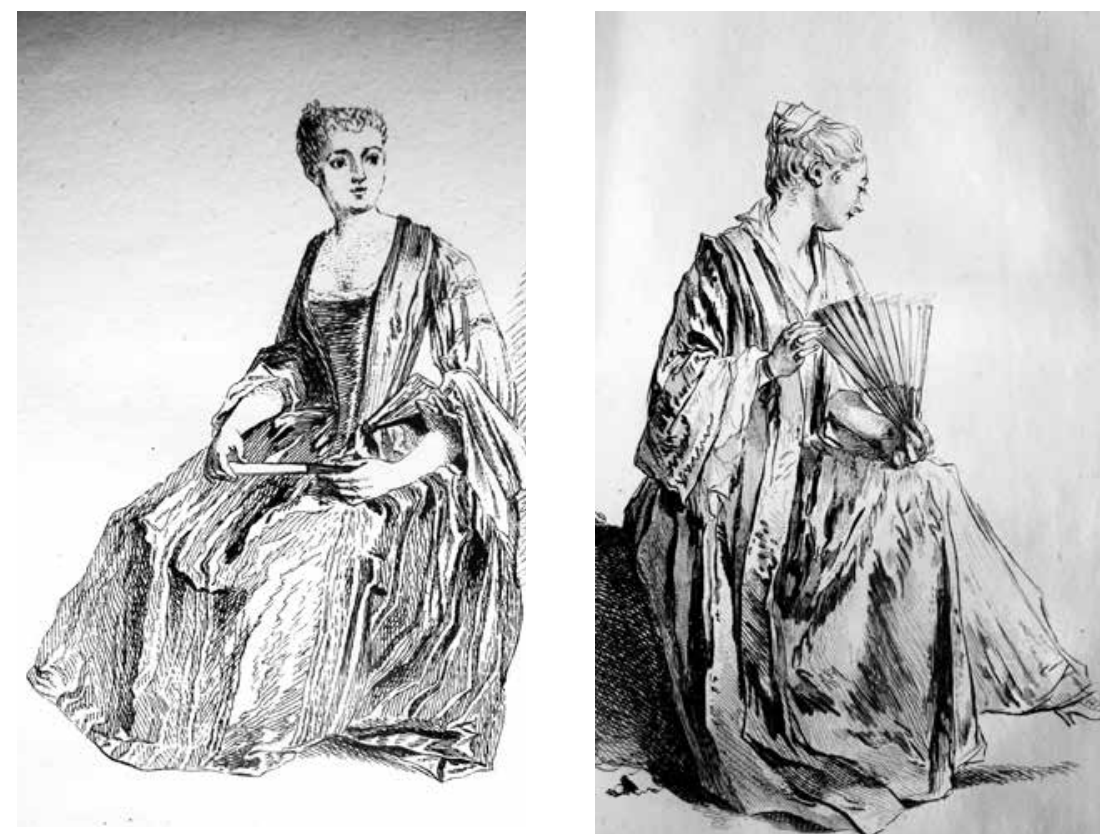

Figuras 11 e 12 - Prancha 130 e Prancha 7 do Tomo I das Figuras de Diferentes Caracteres. Fonte: Arquivos do Museu do Louvre. Coleção Edmond de Rothschild. Paris. Fotografia: acervo pessoal.

Contudo, os trajes representados por Watteau sempre deixam algumas dúvidas, que se tornam território fecundo para reflexão. Por exemplo: em alguns casos, a mistura entre roupas da moda e figurinos teatrais é tão intrincada que se torna dificil estabelecer, à primeira vista, se determinadas figuras são atrizes ou damas da sociedade. Será preciso analisar - minuciosamente e em conjunto - os pormenores do traje e a atitude do personagem para inferir sua identidade de maneira mais precisa.

Apesar de todas as interpretações pessoais, refrações e mesmo criações fantasiosas que Watteau incorpora em suas imagens, em certa medida, ele também apresenta a moda de seu tempo. Suas obras contêm, por exemplo, diversas representações do vestido volante, usado em sua época - representações estas que se tornaram icônicas. Watteau representou esse traje com tamanho detalhe e beleza que seu nome acabou associado à peça de roupa - embora esta não tenha sido uma criação sua. Se o vestido volante marca o universo contemporâneo do artista, outras representações nos relembram que há tempos diversos misturados em cada imagem. Às vezes, um vestido claramente marcado como do século XVIII surge em combinação com um acessório emprestado do século XVl; um penteado já fora de moda podia coroar uma figura coberta por tecidos e ornamentos em perfeita consonância com a época em que a imagem foi produzida. 0 resultado dessa mescla nada tem de caricato; pelo contrário, a convergência e sintese de temporalidades gera um tipo específico de elegância, que pode inclusive parecer plenamente realista àqueles que não conhecem a fundo os modismos do início do século XVIII.

Além disso, Watteau traduz em imagens uma ideia profundamente arraigada em sua época: o desejo de elegância universal. Os seus pastores e pastoras, bem como seus camponeses e camponesas, se vestem de maneira demasiadamente elegante, o que lhes dá um ar irreal. Na obra de Watteau, até mesmo a visão de um pedinte esfarrapado tem algo de agradável. Esse fator de irrealidade, contudo, aponta para uma construção mental da época. Por meio desse exagero de sofisticação e delicadeza, em que até a pobreza e a miséria são transfiguradas por um espirito de refinamento, Watteau retratava uma atitude específica das elites: 0 flerte lúdico com a simplicidade, que era sempre apenas um flerte, um artificio, um jogo. A sofisticação sofisticava-se ao fingir-se de simples. 
Se Watteau mesclava acessórios passadistas aos trajes contemporâneos, também encontramos em suas imagens certos elementos que só se tornariam comuns décadas mais tarde. Afinal, as imagens de Watteau criam a moda ou elas representam modelos que já eram correntes? Não podemos afirmar categoricamente que Watteau tenha previsto ou antecipado modismos. Contudo, é interessante notar que ele apresenta muitas mulheres com a cintura marcada pelo corpete, o que não era comum na época em que essas imagens foram produzidas. $\mathrm{Na}$ década de 1720, o espartilho era usado por baixo do vestido volante, que 0 dissimulava. A cintura mais aparente e afinada começa a aparecer em torno de 1730 e torna-se mais evidente apenas na década de 1740 - quase vinte anos depois da morte do artista. Da mesma maneira que Watteau manipula os tempos na imagem e no traje, ele também transcende os limites de espaço. As roupas que aparecem em suas imagens não são apenas francesas, mas também italianas, holandesas e até inglesas. Naquela época, a moda ainda não era a mesma em todos os lugares e guardava peculiaridades regionais; mesmo assim, 0 artista borra as fronteiras. Por isso, a análise das imagens leva-nos à conclusão de que Watteau não pode ser interpretado apenas como representante da moda francesa de seu tempo, pois pensar assim seria muito redutor.

Convergência de temporalidades, transgressão de limites espaciais; jogos de olhares, oscilações de tecidos, abrir e fechar de leques. Ao analisarmos a moda na produção artística de Watteau, uma palavra acaba surgindo como sintese das múltiplas leituras possiveis: movimento. A imagem é movimento; assim o são, também, a moda e a graça (frequentemente associada ao nome do artista). Tudo isso se combina para dar forma à expressão visual de Watteau, uma expressão móvel e que, por isso mesmo, guarda sempre uma impressão fugidia. 0 artista não cria diretamente uma nova moda, mas cria um movimento entre diferentes temporalidades da moda, entre espaços diversos, e entre o universo vestimentar e as artes. A cintura marcada pelo corpete, que surge nas imagens de Watteau antes de aparecer como hábito de vestimenta, pode ter sido criada pelo artista com base em suas diversas fontes imagísticas, como os figurinos de teatro ou as roupas de outros tempos e lugares.

Aby Warburg mostrou que a própria história da arte é um saber em movimento; por meio dessa constatação, ele abriu e multiplicou seus objetos de análise, as possiveis interpretações, os métodos e as teorias (DIDI-HUBERMAN, 2013). 0 livro de Philipe Michaud, primeira obra sobre Warburg em língua francesa, dedica-se a analisar a questão do movimento nas imagens (MICHAUD, 2013). Nele, o movimento é visto simultaneamente como objeto e como método, como uma caracteristica intrinseca das obras de arte e um desafio à própria história da arte. 0 percurso do pensamento que leva à noção da imagem em movimento inicia com as análises realizadas por Warburg da obra de Botticelli e a hipótese das sobrevivências das expressões gestuais antigas. Com essa reflexão, Warburg abriu a possibilidade de novas formas de interpretação da história da arte, que ele considerava "um saber em movimento das imagens, saber em extensões, em relações associativas, em montagens sempre renovadas, e não mais um saber em linhas retas, em corpos fechados, em tipologias estáveis" (DIDI-HUBERMAN, 2013, p. 19).

Nas reflexões sobre o conceito de moda, a ideia de movimento também tem papel importante. 0 princípio básico do pensamento em torno desse fenômeno é a percepção da busca constante pela novidade. Segundo Daniela Calanca, "a moda apresenta uma dicotomia temporal entre o 'velho' e o 'novo', o presente e 0 passado, a imobilidade e a mobilidade" (CALANCA, 2008, p. 11). Acredito que, mais do que congregar apenas duas temporalidades, a moda, assim como a imagem, é formada pelo choque de múltiplos tempos. A urgência por novidades constantes leva o fenômeno a um eterno movimento de mudanças, mas também de permanências. As permanências não são estáticas: também elas se movem. 
Com tudo isso em mente, já não podemos nos contentar com uma definição da moda como simples distinção social. Lipovetsky observa que tal definição seria insuficiente para explicar a lógica da inconstância, sempre presente no fenômeno da moda. Aqui, vale recordar um ponto recorrente nas definições sobre a moda, sua associação com a modernidade. A moda seria uma manifestação irracional do funcionamento moderno, uma exaltação da mudança pela mudança. Segundo Svendsen, foi no século XVIII que a ideia do moderno, enquanto sinônimo de novo, tornou-se um valor em si mesmo. Dai a necessidade de perseguir a novidade no vestuário para mostrar-se perenemente moderno. A renovação constante na moda é uma expressão de seu movimento; ela nunca é, mas está num constante estado de vir a ser.

É por causa dessa mutabilidade, dessa constante construção que se faz ao longo do tempo, no depósito de camadas da memória sobre a imagem, que elas podem e devem ser revistas. Sob o ângulo da moda, com todas as leituras que desperta e possibilita, tratei de lançar luz sobre o conjunto das Figuras de Diferentes Caracteres, que ainda não foi alvo de um número exaustivo de pesquisas. Não tentei, com isso, paralisá-las em definições ou tipologias cristalizadas. Pelo contrário, tratei de respeitar e acompanhar a graça que as impregna. Ao perceber que toda a experiência imagética é permeada pelo movimento, podemos, quem sabe, tentar capturar - sem congelar - a agitação muda que permeia as figuras do artista, que seguem nos intrigando e nos encantando. 0 maior desafio é tentar pensar a produção de um artista por meio da moda, considerando esta uma esfera do saber capaz de despertar novas indagações no campo da imagem. 


\section{NOTAS}

[1] LIMA, Laura Ferrazza de. Na trama das aparências: moda e arte na obra de Antoine Watteau (1684-1721). Porto Alegre, 2015. Tese (Doutorado) - Programa de Pós-Graduação em História da PUC-RS. 0 presente artigo é parte do resultado final da tese de doutorado aqui referida. A mesma recebeu financiamento do CNPq e foi feito estágio sanduíche na Universidade Paris I - Sorbonne, em História da Arte, financiado pela Capes.

[2] São inúmeros os autores que mencionam tal relação, entre eles: GONCOURT, Edmond et Jules. Arts e artistes. Paris: Hermann, 1997. DACIER, Émile; VUFLART, Albert. Jean de Jullienne et les graveurs de Watteau au XVIlle siècle. Paris: Publication de la société pour l'étude de la gravure française, 1921. 4 v. LAUTERBACH, Iris. Antoine Watteau. Colônia: Taschen, 2010. GLORIEUX, Guillaume. Watteau. Paris: Citadelles \&t Mazenod, 2011. BÖRSCHSUPAN, Helmut. Antoine Watteau (1684-1721). Londres: H.F. Ullman, 2007.

${ }^{[3]}$ Refiro-me aqui aos dois autores citados diretamente na sequência do texto, SVENDSEN e LIPOVETSKY.

\section{REFERÊNCIAS}

BAUMER, Franklin L O pensamento europeu moderno. Vol. I - Séculos XVII e XVIII. Vila Nova de Gaia: Edições 70, 1990.

BÖRSCH-SUPAN, Helmut. Antoine Watteau (1684-1721). Londres: H.F. Ullman, 2007.

BOUCHER, François. Historia del traje en Occidente. Barcelona: Editora Gustavo Gili, 2009.

CALANCA, Daniela. História social da moda. São Paulo: Senac, 2008.

DIDI-HUBERMAN, Georges. A imagem sobrevivente: história da arte e tempo dos fantasmas segundo Aby Warburg. Rio de Janeiro: Contraponto, 2013. Hidalgo, 2011.

Ante el tiempo: historia del arte y anacronismo de las imágenes. Buenos Aires: Adriana

0 que vemos, o que nos olha. São Paulo: Editora 34, 2010.

JAMAIN, Claude. Watteau, la grâce du geste. In: TOUTAIN-QUITTELIER, Valentine et RAUSEO, Chris (Orgs.). Watteau au confluent des arts: esthétiques de la grâce. Rennes: Presses Universitaires de Rennes, 2014.

LEVEY, Michael. Del rococó a la revolución. Madri: Destino, 1998.

LIPOVETSKY, Gilles. 0 império do efêmero: a moda e seu destino nas sociedades modernas. São Paulo: Companhia das Letras, 2003.

MICHAUD, Philippe-Alain. Aby Warburg e a imagem em movimento. Rio de Janeiro: Contraponto, 2013.

NORBERG-SCHULZ, Christian. Architecture du baroque tardif et rococo. Milão: Gallimard, 1997.

POULOT, Dominique. Les lumiéres. Paris: PUF, 2000.

PRAVIS, Patrice. Prefácio. In: MARIVAUX. Le jeu de l'amour et du hasard. Paris: Librairie Générale Française, 1999.

ROCHE, Daniel. A cultura das aparências: uma história da indumentária (séculos XVII-XVIII). São Paulo: SENAC, 2007.

RUPPERT, Jacques; GOURGUET-BALLESTEROS, Pacale; et. all. Le costume français. $3^{\text {a }}$ ed. Paris: Flammarion, 2007.

SAMAIN, Etienne. Aby Warburg. Mnemosyne. Constelação de culturas e ampulheta de memórias. In: SAMAIN, Etienne (Org.). Como pensam as imagens. Campinas: Editora da Unicamp, 2012. p. 51-80.

SCHMITT, Jean-Claude. 0 corpo das imagens: ensaios sobre a cultura visual na Idade Média. Bauru: EDUSC, 2007.

SVENDSEN, Lars. Moda: uma filosofia. Rio de Janeiro: Zahar, 2010. 